\title{
Shifting from rice production to shrimp culture in coastal zones of Khulna: Determination of the determinants
}

\author{
M. Anisuzzaman, M. A. Islam*, K. M. M. Rahman and M. S. R. Shetu \\ Department of Agricultural Statistics, Bangladesh Agricultural University, Mymensingh-22012, Bangladesh \\ *E-mail: maislam_soton@yahoo.com)
}

\begin{abstract}
This study aimed to investigate the determinants of shifting to shrimp culture from rice cultivation in coastal zones of Khulna district by using primary data collected from the four upazillas of Khulna, namely, Batiaghata, Dacope, Dumuria, and Paikgacha. Along with bivariate analysis, single-level binary logistic regression was carried out to identify the determinants of shifting. Through the bivariate analysis it had found that among all variables considered, some variables, precisely, amount of land holdings, access to credit, contact with GOs/NGOs, intrusion of saline water, perception of profitability of shrimp, and water logging had significant relation with shifting to shrimp culture. Similarly, the binary logistic regression had identified five significant determinants of shifting from rice cultivation to shrimp culture: occupation, land holding, access to credit, intrusion of saline water, and water logging.
\end{abstract}

Keywords: Coastal zones, Climate change, Salinity and Water logging, Rice production, Shrimp culture

\section{Introduction}

Production of rice is a vital issue of Bangladesh, both in terms of providing the employment opportunity and fulfilling the dietary requirements of its population. Undoubtedly, with the increased use of modern farming methods the overall production of rice has been increasing significantly for over the last couple of decades. However, the production of rice is very susceptible to the climatic phenomenon and their effects. Rice production, particularly, in the coastal zones of Bangladesh is more vulnerable to climate change than other parts of the country because of geographical location and other geo-morphological features. The coastal zones experience frequent natural disasters, which cause huge loss of lives, impairment to the infrastructures and economic assets. Moreover, climate change has adverse impact on people living in coastal areas.

It follows that the production of rice in coastal zones of Khulna, apart of the largest delta in the world, is affected by the intrusion of various degrees of salinity. Thus, agricultural land use in coastal areas of Khulna is very poor, which is much lower than country's average cropping intensity. Salinity causes unfavorable environment and hydrological situation that restrict the normal rice production throughout the year in those particular areas.

At present, cultivated rice varieties may not be able to withstand and produce optimum yield with the increased salinity. The food production does not seem to have a better future in the event of a climate change. In Bangladesh, rice production may fall by $10 \%$ and wheat by $30 \%$ by 2050 (IPCC, 2007). Salinity intrusion, particularly, due to sea level rise will decrease agricultural production by unavailability of fresh water and soil degradation. Salinity also decreases the terminative energy and germination rate of some plants (Ashraf et al., 2002).

Eventually, rice production is decreasing in these coastal zones where the overall demand for food supply is increasing. Thus, shrunken food production will cause food shortage leading to health hazards. Since cultivable lands of the coastal areas have being engulfed every year by the salinity intrusion, the existing rice production has been reduced due to inability of the rice variety to cope well with the presence of dense salinity. Admittedly, climate change is posing serious threat to ensuring food security and endangering the poverty-stricken coastal farmers to become more impoverished. However, as an important adaptation regionally backward people of the coastal area are often bound to change their professions and practices for their survival. The farmers of the coastal area, in a large extent, are shifting 
to fish culture from rice production. For averting the risk of being unemployed or keeping the existing cultivable lands as fallow, the farmers are engaging in shrimp farming. In search of a way to mitigate potential losses and also to improve amid difficulties, farmers living in coastal area are shifting to shrimp cultivation. In addition, shrimp is convenient to cultivate even with the presence of intense salinity.

Shrimp aquaculture in the coastal zones is expanding rapidly in agricultural lands; especially areas which were mainly used for rice production are being converted into aquaculture ponds. Shrimp areas in Bangladesh have already expanded from 51812 ha in 1983 to 137996 ha in 1994 and to 141353 ha in 2002 (DoF, 2002). Earlier shrimp farming was practiced, particularly, in the areas which were inundated with excess salinity. However, there are other factors are also forcing farmers to shift to shrimp cultivation in addition to the intrusion of salinity. Hence, it is very important to find the determinants of shifting in the above direction.

The overall objectives of the study attempted at determining the reasons for shifting from rice cultivation to shrimp cultivation.

\section{Materials and Methods}

Description and selection of the study area: Khulna is situated in the southern part of Bangladesh, and lies south of Jessore and Narail, East of Satkhira, West of Bagerhat and North of the Bay of Bengal with an area of 4394.46 square kilometer and consists of 9 upazilas (BBS, 2012). The climate and rainfall distribution of Khulna is dominated by the southwest monsoon of the Indian Ocean. Notably, the post monsoon is hot and humid, with occasional thunderstorms, cyclones and storm surges and OctoberNovember is associated with tidal wave severally affect the coastal area, when crops, livestock, property and human lives are lost (Ali, 2006).

These study areas were selected to represent the communities that are affected by climate uncertainty, tropical cyclones and storm surges to different degrees. The communities were selected for the following reasons: firstly, they fall within the coastal saline area of Bangladesh where there are frequent shortages of food due to uncertainty of rainfall and lack of fresh irrigation water. Secondly, the area provides an opportunity to study impacts associated with climate change and vulnerability on crop and livestock. Evidently, the farmers who shifted from rice to shrimp farming were available in these areas.

Sampling and data collection: The study was based on primary data collected from four upazillas of Khulna district - Batiaghata, Dumuria, Dacope, and Paikgacha. Among these upazillas a total of 100 farmers were chosen purposively for the study. Initially 20 farmers who had cultivated rice and afterwards 80 farmers who had shifted to shrimp culture from rice production had been selected purposively (Table 1). The 20 farmers in the first category, i.e., rice cultivator, were entirely engaged in the production of rice. The other 80 farmers in the second category had been shifted to shrimp culture from rice production; thereby, their lands were no longer available for rice production.

Pre-tested structured interview schedule had been used to collect data from the households. Prior to starting of interview, each respondent was given a brief description about the nature and purpose of the study. For the study, data were collected during the period February to March 2014. After collection of necessary information, the schedules were carefully checked, scrutinised and edited to avoid irrelevant information. Responses of the completed questionnaires were numerically coded and analysed.

Analytical method: The differentials of shiftingto shrimp cultivation from rice production were studied employing cross-tabulation analysis and the predictors of shifting had been determined by using singlelevel binary logistic regression model.

Bivariate analysis and chi-square test of independence of attributes: Bivariate analysis can be helpful in testing simple hypotheses of association and causality - checking to what extent it becomes easier to know and predict a value for the dependent variable if we know a case value of the independent variable. In a bivariate analysis, the use of percentage is an advantageous first step for studying the relationship between two variables viz., dependent and independent variables. 
The Chi-square statistic is the primary statistic used for testing the statistical significance of the crosstabulation table. Chi-square test can be used to test the independence of two or more attributes. For testing the hypothesis of independence of two attributes, an observed set of frequencies are compared with a corresponding set of frequencies that are expected under the null hypothesis.

Let $O_{i j}(i=1,2, \ldots, r$ and $j=1,2, \ldots, k)$ denote the observed frequencies and $E_{i j}(i=1,2, \ldots, r$ and $j=1,2, \ldots, k)$ denote the expected frequencies. Then the test statistic, $\chi^{2}$ is defined as: $\chi^{2}=\sum_{i=1}^{r} \sum_{j=1}^{k} \frac{\left(O_{i j}-E_{i j}\right)^{2}}{E_{i j}}$, which is approximately distributed as $x^{2}$ with $(r-1)(k-1)$ d.f.

For tables with two rows and two columns or with any number of rows and columns, the value of Pearson chi-square and likelihood ratio chi-square can be used to test the null hypothesis of independence of two attributes.

Binary logistic regression: Logistic regression measures the relationship between a categorical dependent variable and one or more independent variables, which are usually (but not necessarily) continuous, by using probability scores as the predicted values of the dependent variable. Single binary logistic regression model had been fitted to find out the determinants of shifting to shrimp cultivation from rice production in the intended study areas. The study has considered the binary response $Y_{i j}$ which equals 1 if the farmer $i$ in the community $j$ hasshifted and 0 otherwise. Then the probability that the farm household has experienced positive change is $P_{i j}=P_{r}\left(Y_{i j}=1\right)$. If $k$ independent variables

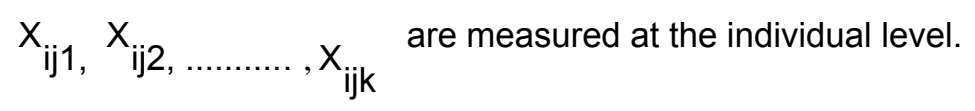

\section{Results and Discussion}

Socioeconomic Characteristics of the Coastal Farmers: The socioeconomic characteristics of the farmers in the study areas, particularly, educational status, occupation, land ownership pattern, and et cetera have been briefly illustrated below:

Education and Literacy of Farm Households: Education is an influencing factor of the decision making process in agricultural production. It makes a farmer more capable of managing scare resources. In this study, the farmers having at least 5 years of schooling have been considered as literate farmers. Approximately 63.0 percent of the respondents were literate. Conversely, around 37.0 percent of the farmers were found illiterate. Literate family members, besides households' head, also play an important role in farming operations. Nearly 63.3 percent of the households had literate family member of one to three persons. Another 35.8 percent of the families had literate family member of four to six persons. Merely 0.83 percent of the households have literate family member of seven to ten persons.

Occupation of the Farmers: The inhabitants of the coastal zone mainly depend on agricultural activities, i.e., rice production, shrimp farming. Most of the farmers consider shrimp farming or rice production as primary occupation, and only few of them are engaged in business as their primary occupation. Some farmers, however, are engage in more than two activities. Nearly 88 percent of the surveyed respondents were engaged in agricultural activities, where only 12 percent involved in business, small business (grocery shop, vegetables selling, et cetera).

Land Holding and Land Use Pattern of the Farmers: The land holding of the chosen farmers was defined as the sum total of all types of land possessed by the farmers and having legitimate and also using right. About 36 percent of the farmers had holdings of 5 to 49 decimal and on the contrary only 8 percent of the farmers possessed land of above 750 decimal. Approximately 56 percent of the 
respondents had possessed land of 50 to 749 decimal. The average farm size of the sampled farmers was 320 decimal of which crops, including rice and shrimp, accounted for 278.1 decimal, 10 decimal occupied by vegetables, and 31.8 decimal had belonged to homestead area. It was observed that the negligible area was allocated for the production of vegetables in the study area.

Sources of Household Income and Total Assets of the Selected Farmers: Household income is a measure of the combined incomes of all family members of a particular household. It includes every form of income, e.g., income from agriculture, business profit, salaries and wages, retirement income, etc. People of the studied area mainly earned from the agriculture but some of them were engaged in small business, rickshaw/van pulling and so on.

Family asset is indispensible for determining the nature of affluence in household level or in any other levels. Assets, in this study, included land of the farmer, value of house, furniture, materials for farming operation, deposits in bank or in other forms. About 68 percent of the respondents had assets worth of Tk. 51,000 to Tk. 250,000 Taka. Only 9 percent of farmers possessed assets worth of Tk. 251,000 to Tk. 500,000 . Rest of 23 percent respondents had assets worth of Tk. 5,000 to Tk. 50,000.

Table 1. Distribution of respondents according to the farming practices

\begin{tabular}{lcc}
\hline \multicolumn{1}{c|}{ Study area } & Name of the farming & Number of respondents \\
\hline Batiaghata & Rice Production & 10 \\
Dumuria & Shifted shrimp culture & 20 \\
Dacope & Shifted shrimp culture & 30 \\
Paikgacha & Rice Production & 10 \\
\multicolumn{1}{c}{ Total } & Shifted shrimp culture & 20 \\
\multicolumn{2}{c}{ Thifted shrimp culture } & 10 \\
\hline
\end{tabular}

Differentials of the Shifting: Farmers' age has been divided into three categories, namely, young group (20-35 years), middle-aged group (36-50), and aged group (above 50 years). The relationship between different age groups and shift to shrimp was found insignificant. However, about 84.6 percent of the aged farmers had been shifted to the shrimp culture. This was the highest percentage of shifting among all age groups (Table 2).

Two types of professions, namely, agricultural activities, and small business were significantly associated with the shift. It was observed that 95.5 percent of the respondents were engaged in business (agriculture was the secondary occupation) had been moved to shrimp culture. However, about 78.2 percent of the respondents who were engaged in agricultural activities had converted their paddy field into pond for shrimp culture.

The relationship between farm size and shift had turned out to be statistically significant at $1 \%$ level of significance. The highest percentage of respondents (95 percent) who possessed land of more than 750 decimal reported that they had shifted from rice production to shrimp culture. In contrast, about 53.7 percent of respondents had moved to shrimp culture who entitled to land of less than 49 decimal.

The number of family members was insignificantly related to the shift. About 83.6 percent of the respondents having family size of 1 to 6 persons had shifted to shrimp culture. But75.5 percent of the respondents of other category, i.e., family size of 7 to 14 persons, had shifted to shrimp culture. From cross tabulation an insignificant relationship between education of the farmers and shift to shrimp culture had been identified. About 78 percent of literate farmers had shifted, whereas it was nearly 22 percent for the illiterate farmers.

Access to necessary credit is important to maintain uninterrupted farming operations. The relationship between access to credit and the shift had been found to be statistically significant at $1 \%$ level. Approximately 90 percent of the farmers having access to credit had shifted to shrimp culture form the rice production. On the other hand, 70 percent of the farmers not having the access to credit had shifted. 
Table 2. Differentials of shifting from rice production to shrimp culture

\begin{tabular}{|c|c|c|c|}
\hline \multirow[t]{2}{*}{ Name of Independent Variables } & \multirow{2}{*}{$\begin{array}{l}\text { Frequency } \\
\text { (N) }\end{array}$} & \multicolumn{2}{|c|}{ Shift from rice to shrimp (\%) } \\
\hline & & Yes & No \\
\hline \multicolumn{4}{|l|}{ Age of the farmer $(p=.750)$} \\
\hline $21-35$ years & 45 & 77.7 & 22.3 \\
\hline $36-50$ years & 29 & 79.3 & 20.7 \\
\hline Above 50 years & 26 & 84.6 & 15.4 \\
\hline \multicolumn{4}{|l|}{ Occupation $(p=.046)$} \\
\hline Agricultural Activity & 86 & 78.2 & 21.4 \\
\hline Business & 14 & 95.5 & 4.5 \\
\hline \multicolumn{4}{|l|}{ Land holdings $(p=.001)$} \\
\hline 5-49 decimal & 12 & 53.7 & 46.3 \\
\hline 50-749 decimal & 78 & 68.5 & 31.5 \\
\hline Above 750 decimal & 10 & 95.0 & 5.00 \\
\hline \multicolumn{4}{|l|}{ Family member $(p=.225)$} \\
\hline $1-6$ & 55 & 83.6 & 16.4 \\
\hline $7-14$ & 45 & 75.5 & 24.5 \\
\hline \multicolumn{4}{|l|}{ Education of the farmer $(p=.555)$} \\
\hline Literate & 78 & 82.5 & 17.5 \\
\hline Illiterate & 22 & 72.6 & 27.4 \\
\hline \multicolumn{4}{|l|}{ Access to credit $(p=.001)$} \\
\hline Yes & 50 & 90.0 & 10.0 \\
\hline No & 50 & 70.0 & 30.0 \\
\hline \multicolumn{4}{|l|}{ Contact with GO/NGO $(p=.015)$} \\
\hline Yes & 49 & 89.7 & 10.3 \\
\hline No & 51 & 70.5 & 29.5 \\
\hline \multicolumn{4}{|l|}{ Intrusion of saline water $(p=.001)$} \\
\hline Yes & 85 & 86.5 & 13.5 \\
\hline No & 15 & 53.3 & 46.7 \\
\hline \multicolumn{4}{|l|}{ Shrimp is profitable $(p=.040)$} \\
\hline Yes & 79 & 81.0 & 19.0 \\
\hline No & 21 & 76.1 & 23.9 \\
\hline \multicolumn{4}{|l|}{ Water logging $(p=.001)$} \\
\hline Yes & 85 & 80.0 & 20.0 \\
\hline No & 15 & 80.0 & 20.0 \\
\hline \multicolumn{4}{|l|}{ Receiving of training $(p=.06)$} \\
\hline Yes & 35 & 94.2 & 5.8 \\
\hline No & 65 & 72.3 & 27.7 \\
\hline Total & 100 & 80.0 & 20.0 \\
\hline
\end{tabular}

Note: $p$ values are based on chi-square test. Row percentages for shift status add to 100

Relationship between contact with the NGO for farm management consultancy and shift to shrimp cultivation was found to be significant at $5 \%$ level. About90 percent of the farmers having contact with NGO had switched to shrimp culture form the rice production. On the contrary, nearly70 percent of farmers not having the same contact with NGO had shifted to shrimp culture. Salinity intrusion was found to be significant in relation to the shift. About 86 percent of farmers after having intruded by saline water had shifted to shrimp culture. On the contrary, 53.3 percent of farmers not having the similar intrusion had shifted to shrimp culture. 
The relationship between farmers' positive perception about the profitability of the shrimp and the shift had been identified to be statistically significant at $5 \%$ level. Exactly 81 percent of the respondents having the positive perception about profitability of shrimp had shifted towards shrimp culture from rice production. On the other hand, nearly 76 percent of the farmers shifted to shrimp even after not having the positive perception about profitability of shrimp.

In many cases water in land stays throughout the year, especially in lands beside canal or rivers. Nonetheless, water is vital to grow plant, but waterlogged lands are not suitable for rice production. Water logging impedes to produce adequate yields of rice. In cross tabulation it was found that there existed a significant association between water logging and shift to shrimp. Exactly 80percent of the respondents had moved to shrimp culture after being perturbed by the water logging conditions in their crop lands. Similarly, 80 percent of the farmers had shifted to shrimp even not having intruded by prolonged water.

Provision of training is an indispensible tool for ensuring smooth farming operation. Usually training is provided by different NGOs, agricultural extension officers, fish spawn producers, and so forth. The association between receiving training and shift to shrimp culture turned out to be statistically significant at $5 \%$ level. Having received training nearly 94 percent of the farmers had shifted. On the other hand, shifting rate was only 72.3 percent for the farmers not having the same training about shrimp cultivation.

Determinants of Shifting: In order to find out the factors that had impact on shifting to shrimp cultivation from rice production of the households in coastal area, a binary logistic regression model had been estimated. The outcome variable was dichotomous in this study. Earlier from the cross tabulation several significant independent variables have been identified, and in order to execute binary logistic regression only significant variables found from the cross tabulation have been used. The dependent variable was the shift to shrimp culture from rice production. The scores assigned as 1 and 0 to the responses 'farmer has shifted to shrimp culture' and 'farmer has not shifted to shrimp culture' respectively.

Generally, inclusion of a large number of covariates in an analysis may result muticollinearity problem. Considering this, the analysis considered the significant covariates that were free from multicollinearity. Among the variables considered in regression analysis, five variables, such as, occupation, land holdings, access to credit, intrusion of saline water, and water logging had significant effect on shifting. The results of the binary logistic regression have been shown in Table 3.

The variable of occupation of the households' head has been come out to be a significant determinant of shifting. The binary logistic regression has shown that the respondents engaged in business as primary occupation and agricultural activities as s secondary occupation were 4.28 times more likely to shift to shrimp from rice than the respondents engaged only in agricultural activities. Small and medium businessmen, in general, were more affluent than the farmers. They could afford necessary money to continue farming operations. Farmers, on the other hand, did not earn enough money to operate farming operations.

Farm size has been found as an influencing factor of shift to shrimp culture. The farmers having land holdings of 50 decimal to 749 decimal were 4.41 times significantly more likely to move to shrimp culture than their counterparts (farmers having land holdings of 5 decimal to 49 decimal). However, large farmers having land holding of more than 750 decimal were 9.87 times likely to shift to shrimp culture than the farmers in the referral category (farm size of 5 decimal to 49 decimal). In general, additional land provided the ample opportunity to cultivate dimensional crops in rotation. Moreover, it enhanced the freedom to participate in alternative farming practices, which were limited or impossible otherwise.

The access to credit was a significant factor (at 1\% level) of shifting. It was been found that respondents not having the access to credit were .090 times less likely to shift form rice production to shrimp than the respondents having access to credit. Perpetual monetary support ensures uninterrupted farming practice. But unfortunately poor farmers could spend necessary money in time of needs. Consequently, provision of credit was vital factor to the farmers. 
Table 3. Binary logistic regression model (single level) for the determination of shift to shrimp culture from rice production

\begin{tabular}{|c|c|c|c|}
\hline \multirow[b]{2}{*}{ Independents variables } & \multicolumn{3}{|c|}{ Shift from rice production to shrimp cultivation } \\
\hline & Coefficient $(\beta)$ & $\begin{array}{c}\text { Standard Error } \\
\text { (SE) }\end{array}$ & Odds Ratio \\
\hline $\begin{array}{l}\text { Intercept } \\
\text { Occupation } \\
\text { (r: Agricultural activities) }\end{array}$ & $3.588^{* *}$ & .704 & \\
\hline $\begin{array}{l}\text { Business } \\
\text { Land holding } \\
\text { ( } r: 5-49 \text { Decimal) }\end{array}$ & $1.39^{*}$ & .580 & 4.28 \\
\hline 50-749 Decimal & $1.512^{*}$ & .655 & 4.41 \\
\hline $\begin{array}{l}\text { Above } 750 \text { decimal } \\
\text { Access to credit } \\
(r \text { :Yes) }\end{array}$ & $2.69^{* *}$ & .896 & 9.87 \\
\hline $\begin{array}{l}\text { No } \\
\text { Intrusion of saline wate } \\
(r: \text { Yes) }\end{array}$ & $-2.15^{* *}$ & .663 & .090 \\
\hline $\begin{array}{l}\text { No } \\
\text { Water logging } \\
(r: \text { Yes) }\end{array}$ & $-2.500^{* *}$ & .771 & 0.075 \\
\hline No & $-1.365^{*}$ & .651 & 0.357 \\
\hline
\end{tabular}

Note: $r$ denotes reference category; ${ }^{*} p<0.05$ and ${ }^{* *} p<0.01$ are the levels of significance

The regression analysis had also shown that the salinity intrusion was statistically significant (at $1 \%$ level) factor of shifting. The farmers, whose land had not been intruded by saline water, were 0.075 times significantly less likely to switch to shrimp culture than the farmers whose land had been intruded by salinity.

Prolonged water staying throughout the year in the crop land was another important factor in shifting to shrimp cultivation. Binary logistic regression analysis had shown that water logging condition was significant determinant of shifting. The results had suggested respondents not having waterlogged land were 0.357 times significantly less likely to shift to shrimp culture than the respondents having waterlogged land. Undoubtedly, farmers were bound to convert paddy land into another venture where prolonged water existed; in such cases, shrimp cultivation was a suitable alternative.

\section{Conclusion, Recommendation Policy Implication}

This study has contributed to a better understanding of the reasons for shifting from shifting from rice production to shrimp cultivation. Likewise, it has revealed important determinants shifting, which may interest policy makers as well as academic researchers.

Coastal farmers, in many cases, are not prudent enough in making appropriate adaptation decision. Since most of the coastal farmers or farmers of elsewhere in Bangladesh are illiterate or less educated, they usually do not have the scientific basis on farming practices. Evidently, there are chances of being misguided in taking farming-decision. In many occasions farmers have been switched to shrimp cultivation in lands which were not suitable for shrimp cultivation, but suitable for rice cultivation. In these circumstances, concerned agencies, like, Department of Agricultural Extension, Ministry of Fisheries, and Ministry of Agriculture have roles to play in averting risk that may arise from shifting decision. In order to 
help farmers, they (concerned authority) should identify the land which will be appropriate for shrimp culture or rice production. Only then, farmers can get expected gain from both rice production and shrimp farming. Therefore, if the decision of shifting can be made by the experts, that would be beneficial for the farmers.

Income that comes from engaging in agriculture is not enough to cover production process of certain crops and all the necessary expenses of a household. This seriously hampers the production process and also poses threats to the household members in the context of food security. On the other hand, family and farmers engaging in occupation other than agricultural activities only have the more flexibility to adapt efficiently. Income from other sources than agricultural activities ensures smooth farming operation and benefit of shifting. Therefore, engaging in off-farm income generating activities could be the solution. People of the coastal zone should be thinking of establishing small businesses, focusing on off-farm activities, setting up cottage industries, and so forth. Potential gain from these activities can avert possible losses that may arise in several stages of farming operations.

Larger farmers (according to the farm size) are supposed to be more dominant and affluent in coastal zone. Unlike small and marginal farms, in many cases, larger farms are more efficient in using appropriate farming technology and their gains are usually higher than relatively small size of farm in shifting to shrimp cultivation. Hence, farmers should be encouraged to increase the farm size by initiating co-operation and appropriate measures should be taken by the government in this regard.

Access to credit, evidently, had played a vital role in shifting. More the access farmer had in gaining credit, the more liberty and enthusiasm coastal farmers shown in switching to investment-intensive shrimp cultivation. Therefore, in this regard, concerned stakeholders and GOs and NGOs can initiate appropriate actions, like, providing of necessary credit to farmers.

Regarding intrusion of saline water and water logging, farmer had less liberty in deciding about shifting to shrimp cultivation. They were forced to shift as soon as their lands had engulfed by saline water. However, concerned authority can take initiative in controlling the level of water and also extent salinity from river to farmers' land by building and managing polders, dams or so forth.

\section{Acknowledgments}

Authors are thankful to the Ministry of Science and Technology, the Government of People's Republic of Bangladesh for granting National Science and Technology (NST) Fellowship to conduct this study.

\section{References}

Ali, A.M.S. 2006. Rice to shrimp: land use/ land cover changes and soil degradation in southwestern Bangladesh. Land Use Policy, 23(4): 421-435.

BBS 2012. Statistical Yearbook of Bangladesh. Bangladesh Bureau of Statistics. Ministry of Planning, Government of Bangladesh, Dhaka.

PCC 2007. Mitigation, contribution of working group iii to the third assessment report of the Intergovernmental Panel on Climate Change (IPCC). Cambridge University Press, UK.

Ashraf, M.Y., Sarwar, G., Ashraf, M., and Sattar, A. 2002. Salinity induced changes in $\alpha$-amylase activity during germination and early cotton seedling growth. Biologia Plantarum, 45(4): 589-591.

DoF 2002. Fisheries resources survey system. Department of fisheries, Government of Bangladesh. 